\title{
SOCIOECONOMIC POSITION AND MALNUTRITION AMONG OLDER ADULTS: RESULTS FROM THE FRADEA STUDY
}

\author{
E.O. HOOGENDIJK ${ }^{1}$, T. FLORES RUANO ${ }^{2,3}$, M. MARTÍNEZ-REIG ${ }^{2,3}$, M. LÓPEZ-UTIEL ${ }^{2}$, \\ S. LOZOYA-MORENO ${ }^{2}$, E. DENT ${ }^{4,5}$, P. ABIZANDA ${ }^{2,3}$
}

\begin{abstract}
1. Department of Epidemiology \& Biostatistics, Amsterdam Public Health research institute, VU University medical center, Amsterdam, the Netherlands; 2. Department of Geriatrics,

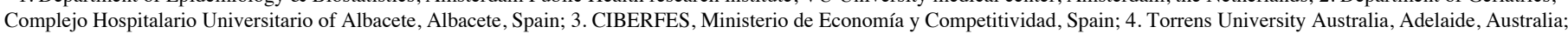
5. Baker Heart and Diabetes Institute, Melbourne, Australia. Corresponding author: Emiel O. Hoogendijk, Department of Epidemiology \& Biostatistics, Amsterdam Public Health research institute, VU University medical center, Amsterdam, the Netherlands, Tel: +31204443146, Email: e.hoogendijk@vumc.nl
\end{abstract}

\begin{abstract}
Objectives: Low socioeconomic position (SEP) is related to many health-related conditions in older adults. However, there is a lack of knowledge on the association between SEP and malnutrition, a condition with serious consequences for older people in terms of quality of life and adverse health events. In the current study, we investigated socioeconomic inequalities in malnutrition and sub-domains of malnutrition in a sample of Spanish older adults. Design: Cross-sectional population-based study. Setting: Urban area of Albacete, Spain. Participants: 836 participants over age 70 from the first measurement wave (2007-2009) of the Frailty and Dependence in Albacete (FRADEA) study, a population-based cohort study. Measurements: Educational level and occupational level were the indicators of SEP. Nutritional risk was measured with the Mini Nutrition Assessment ${ }^{\circledR}$ Short Form (MNA®-SF). Logistic regression analyses were performed. Results: For both socioeconomic indicators there was a statistically significant association with nutritional risk (OR low education $=1.99,95 \% \mathrm{CI}=1.18-3.35$; OR low occupational level=1.71, 95\% $\mathrm{CI}=1.08-2.72)$. However, these associations disappeared after adjusting for age and sex (OR low education $=1.51,95 \% \mathrm{CI}=0.88-2.60$; OR low occupational level $=1.32,95 \% \mathrm{CI}=0.80-2.17)$. In adjusted models, statistically significant associations between SEP and sub-domains of the MNA ${ }^{\circledR}$-SF were observed, but these associations were not consistent across socioeconomic indicators. Conclusions: This study found that malnutrition is a condition that can appear in any older adult, regardless of their socioeconomic group. These findings suggest that interventions to prevent malnutrition in older adults can be targeted at a general older population, and do not have to be SEP specific.
\end{abstract}

Key words: Older adults, malnutrition, nutritional assessment, socioeconomic position.

\section{Introduction}

Older people with a low socioeconomic position (SEP) have a higher risk of various geriatric conditions, and adverse outcomes related to these conditions. This includes, for example, frailty and polypharmacy, which have shown to be more prevalent in older adults with low education or low levels of income (1-3). Another geriatric condition with serious consequences for older people in terms of quality of life and adverse health events is malnutrition $(4,5)$. However, for malnutrition the association with SEP is less well established.

Malnutrition in older adults is being increasingly recognized as a major contributor to early mortality and functional decline (6), with around $5 \%$ of community-dwelling older adults affected, and an additional $30 \%$ at risk of developing the condition (7). There are many well-known risk factors for malnutrition in older people, including swallowing difficulties, early satiation, loss of appetite and multimorbidity $(8,9)$. What is less clear is the association of SEP with malnutrition. Whilst malnutrition is often linked with low education and poverty, the majority of studies supporting this hypothesis are either conducted in developing countries, among children, or in older adults residing in residential care (10-13). The few studies that have been conducted among communitydwelling older adults show mixed results. For instance, an
Italian study found an association between low educational level and nutritional risk (14), yet, on the other hand, a recent Polish study concluded that low educational level was not an independent risk factor of malnutrition (15). Both studies made use of the Mini Nutritional Assessment ${ }^{\circledR}$ Short Form (MNA®-SF), a well-validated multidimensional measurement instrument (16), and the recommended instrument by the European Society of Clinical Nutrition (ESPEN) for malnutrition screening of community-dwelling older people (17). Despite the comprehensive nature of these studies, they did not further investigate socioeconomic inequalities in the sub-domains of the MNA®-SF. It could be that, even when there is no consistency in in the overall association between SEP and malnutrition, there may still be a clear SEP pattern for the sub-domains of the MNA ${ }^{\circledR}-\mathrm{SF}$. These sub-domains include decreased food intake, weight loss, mobility limitations, acute health status (psychological stress/ acute disease), neuropsychological issues (dementia and/or depression) and low body mass index (BMI) - the latter of which can be substituted for calf circumference measurement (16). Knowledge of the relationship between SEP and these sub-domains of malnutrition will build evidence regarding nutritional care for older people, and better position healthcare practitioners to identify and manage malnutrition.

The objective of the current study was to investigate 


\section{THE JOURNAL OF NUTRITION, HEALTH \& AGING@}

socioeconomic inequalities in malnutrition and sub-domains of malnutrition among older adults, using data from the Frailty and Dependence in Albacete (FRADEA) study, a sample of Spanish community-dwelling older adults. Previous work on malnutrition in the same cohort showed that about $30 \%$ of this population was malnourished or at risk of malnutrition, as determined by the MNA®-SF (4).

\section{Methods}

\section{Design and study population}

Cross-sectional data from the first wave (2007-2009) of the FRADEA study were used. FRADEA is a populationbased cohort study among older adults aged 70 and over in the urban area of Albacete in Spain. Details on the methods and characteristics of the study sample have been published before (18). In brief, to obtain a representative sample of a Spanish urban older population, 1172 people aged 70 and over were randomly selected from registered health care holders in the city of Albacete in 2007 ( $\mathrm{n}=18137)$, of which 993 individuals (84.7\%) agreed to participate. Data were collected by faceto-face interviews and clinical measurements at the geriatrics department of the Complejo Hospitalario Universitario in Albacete. This was done by four trained nurses between November 2007 and November 2009. Of the 993 participants included in the FRADEA study, $157(15.6 \%)$ had no valid data on malnutrition. This resulted in a final sample of 836 people included in the current analysis. The FRADEA study received approval by the Albacete health region Independent Ethics Committee and the Albacete University Hospital Ethics Committee. All participants provided signed informed consent.

\section{Measurements}

Our SEP measures included educational level and occupational level. Respondents were asked about their highest level of education. There were five answering categories: illiterate, primary school not completed, primary school completed, secondary school, and university (18). Respondents were also asked about their main occupation during their working life. The Spanish National Classification of Occupations was used to differentiate occupational levels (19). Seven levels were distinguished (inadequately described occupations, unskilled occupations, partly skilled occupations, manual skilled occupations, non-manual skilled occupations, intermediate occupations, and professional occupations). Due to skewed distributions we dichotomized both socioeconomic indicators. Those with primary school or less were distinguished from people with secondary school or more to indicate low and high level of education. Inadequately described occupations, unskilled occupations, partly skilled occupations, and manual skilled occupations were considered as low occupational level, while non-manual skilled occupations, intermediate occupations, and professional occupations were considered as high occupational level.
Nutritional status was measured with the MNA®SF (16). This instrument includes six items which evaluate decreased food intake, weight loss, mobility, acute health status, neuropsychological problems, and anthropometric data (BMI). The summed score of the MNA®-SF ranges between 0 and 14. In the current study, nutritional risk was used as the main outcome measure. This includes all participants who are malnourished or at risk of malnutrition, determined by the recommended cut-off of $<12$ points on the MNA®-SF (4). Subdomains of malnutrition were dichotomized. Decreased food intake was considered present if respondents had a moderate to severe decrease in food intake in the past 3 months due to loss of appetite, digestive problems, or chewing/swallowing difficulties. Weight loss was present if respondents had any weight loss in the past 3 months. Limited mobility meant that an older adult was bed or chair bound, or was able to get out of bed/chair but never goes out. To measure acute disease or psychological stress, respondents were asked whether they suffered from psychological stress or an acute disease in the past 3 months (yes/no). Neuropsychological problems were present if a respondent had dementia and/or depression. Finally, low BMI was defined as a BMI of lower than $21 \mathrm{~kg} / \mathrm{m} 2(20)$.

Other variables to characterize the current study sample included age, sex, Barthel Index, Charlson index, Mini-Mental State Examination (MMSE), and frailty. The Barthel Index provides insight into basal functional status. It is a score from 0 to 100 , where lower scores indicate reduced ability to perform basic activities of daily living, such bathing, grooming, dressing, eating, toilet use, continence, and mobility (21). The presence of comorbidity was summarized with the Charlson comorbidity index (22). Cognitive functioning was measured with the MMSE (range 0-30, with higher scores indicating better cognitive functioning) (23). Frailty was assessed with the criteria of Fried's frailty phenotype (24). Respondents were considered to be frail if at least three out of five criteria were present: weight loss, slow gait speed, low grip strength, exhaustion, and low physical activity, as described in more detail elsewhere (25).

\section{Statistical analysis}

Descriptive analyses were performed to outline details of the study sample. To compare characteristics of participants with a low educational/occupational level with those with a high educational/occupational level, t-tests for continuous variables and chi-square tests for categorical variables were performed respectively. Socioeconomic inequalities in malnutrition were determined using logistic regression analyses, with nutritional risk as outcome measure. For both socioeconomic indicators, two regression models were performed: (i) a univariate model without adjustment for covariates; and (ii) a model adjusted for age and sex. These regression analyses were repeated for each MNA ${ }^{\circledR}-S F$ sub-domain. All analyses were done in IBM SPSS Statistics 22 (IBM Corp. Armonk, NY). 
SOCIOECONOMIC POSITION AND MALNUTRITION AMONG OLDER ADULTS

Table 1

Characteristics of the study sample for the total population and by socioeconomic position

\begin{tabular}{|c|c|c|c|c|c|c|c|c|}
\hline & \multirow{2}{*}{\multicolumn{2}{|c|}{$\begin{array}{c}\text { Total } \\
(\mathbf{N}=\mathbf{8 3 6})\end{array}$}} & \multicolumn{3}{|c|}{ By educational level } & \multicolumn{3}{|c|}{ By occupational level } \\
\hline & & & \multirow{2}{*}{$\begin{array}{l}\text { Low }(\mathrm{N}=\mathbf{7 3 6}) \\
\text { \% or } \mathrm{M}(\mathrm{SD})\end{array}$} & \multirow{2}{*}{$\begin{array}{r}\text { High }(\mathrm{N}=100) \\
\% \text { or } M(\mathrm{SD})\end{array}$} & \multirow[b]{2}{*}{$\mathrm{p}^{*}$} & \multirow{2}{*}{$\begin{array}{l}\text { Low }(\mathrm{N}=707) \\
\text { \% or } \mathrm{M}(\mathrm{SD})\end{array}$} & \multirow{2}{*}{$\begin{array}{l}\text { High }(\mathrm{N}=122) \\
\text { \% or M }(\mathrm{SD})\end{array}$} & \multirow[b]{2}{*}{$\mathbf{p}^{*}$} \\
\hline & $\mathbf{N}$ & \% or M (SD) & & & & & & \\
\hline \multicolumn{9}{|l|}{ Sex } \\
\hline Female & 492 & 58.9 & 71.0 & 29.0 & $<0.001$ & 65.2 & 20.5 & $<0.001$ \\
\hline Charlson comorbidity index & 835 & $1.2(1.4)$ & $1.2(1.4)$ & $1.1(1.7)$ & 0.66 & $1.2(1.4)$ & $1.1(1.4)$ & 0.63 \\
\hline MMSE score & 734 & $24.9(4.8)$ & $24.6(4.9)$ & $26.8(3.2)$ & $<0.001$ & $24.6(4.9)$ & $26.7(3.6)$ & $<0.001$ \\
\hline Frailty, \% yes & 159 & 19.3 & 20.1 & 14.0 & 0.15 & 19.9 & 16.5 & 0.39 \\
\hline \multicolumn{9}{|l|}{ MNA ${ }^{\circledR}-\mathrm{SF}$} \\
\hline Decreased food intake & 137 & 16.4 & 17.1 & 11.0 & 0.12 & 16.8 & 14.8 & 0.57 \\
\hline Weight loss & 166 & 21.0 & 21.9 & 14.1 & 0.08 & 22.5 & 12.8 & 0.02 \\
\hline Limited mobility & 194 & 23.2 & 25.0 & 10.0 & $<0.01$ & 24.5 & 14.8 & 0.02 \\
\hline Acute disease or psychological stress & 178 & 21.3 & 21.4 & 21.0 & 0.93 & 22.6 & 13.9 & 0.03 \\
\hline Neuropsychological problems & 194 & 23.2 & 24.9 & 11.0 & $<0.01$ & 24.1 & 16.4 & 0.06 \\
\hline Low BMI & 32 & 4.1 & 3.8 & 6.0 & 0.31 & 3.1 & 9.9 & $<0.001$ \\
\hline
\end{tabular}

\section{Results}

Table 1 shows the characteristics of the study sample. Malnutrition or the risk of malnutrition was present in $30.3 \%$ of the study population. For the MNA ${ }^{\circledR}$-SF sub-domains, the highest prevalence was observed for limited mobility and neuropsychological problems. Table 1 also shows differences in characteristics by SEP. The prevalence of malnutrition and the risk for malnutrition was lower among higher educated older adults (19\% among higher educated versus $31.8 \%$ among lower educated). Three sub-domains of malnutrition were more prevalent in lower educated people (weight loss, limited mobility, and neuropsychological problems). Furthermore, respondents with a higher educational level were younger, more often male, and had a better functional and cognitive status. Nutritional status also differed by occupational level (21.3\% with nutritional risk or malnutrition among older adults with a high occupational level versus $31.7 \%$ among those with a low occupational level). The MNA®-SF sub-domains weight loss, limited mobility, and acute disease or psychological stress were more prevalent among those with a low occupational level, while low BMI was more often present in people with a high occupational level. Respondents with a higher occupational level were also more often male, and had a better cognitive status.

Tables 2 and 3 present the results of the logistic regression analyses. For both educational level and occupational level socioeconomic inequalities in nutritional risk were observed in the unadjusted model, with a higher risk for malnutrition among lower socioeconomic groups $(\mathrm{OR}=1.99,95 \% \mathrm{CI}=1.18$ 3.35 , and $\mathrm{OR}=1.71,95 \% \mathrm{CI}=1.08-2.27$, respectively). After adjusting for age and sex, the effects of educational level and occupational level were no longer statistically significant (OR $=1.51,95 \% \mathrm{CI}=0.88-2.60$, and $\mathrm{OR}=1.32,95 \% \mathrm{CI}=0.80$ 2.17 , respectively). Since the SEP effects were not statistically significant anymore after controlling for age and sex, no further adjustment for other covariates was applied.

There were also statistically significant associations between SEP and sub-domains of the MNA®-SF (Tables 2 and 3). In adjusted models, limited mobility $(\mathrm{OR}=2.47,95 \% \mathrm{CI}=1.16-$ 5.28) and neuropsychological problems $(\mathrm{OR}=2.11,95 \% \mathrm{CI}$ = 1.09-4.10) were more often observed among lower educated people. For the other indicator of SEP, occupational level, statistically significant associations were present for acute disease/psychological stress and low BMI. Acute disease/ psychological stress was more often present among those with a lower occupational level compared to those with a high occupational level $(\mathrm{OR}=2.08,95 \% \mathrm{CI}=1.18-3.66)$, while a 
Table 2

Associations of educational level with nutritional risk and MNA®-SF sub-domains

\begin{tabular}{|c|c|c|c|c|c|c|}
\hline & \multicolumn{2}{|c|}{ Crude effect } & \multicolumn{4}{|c|}{ Adjusted for age, sex } \\
\hline & Low education & High education (ref.) & & Low education & High education (ref.) & \\
\hline & OR $(95 \% \mathrm{CI})$ & OR $(95 \%$ CI $)$ & $\mathbf{p}$ & OR $(95 \% \mathrm{CI})$ & OR $(95 \% \mathrm{CI})$ & $\mathbf{p}$ \\
\hline \multicolumn{7}{|l|}{ Total score } \\
\hline $\mathrm{MNA} \circledast-\mathrm{SF}<12$ & $1.99(1.18-3.35)$ & 1.00 & 0.01 & $1.51(0.88-2.60)$ & 1.00 & 0.14 \\
\hline \multicolumn{7}{|l|}{ Sub-domains } \\
\hline Decreased food intake & $1.67(0.87-3.22)$ & 1.00 & 0.12 & $1.20(0.60-2.37)$ & 1.00 & 0.61 \\
\hline Weight loss & $1.71(0.94-3.09)$ & 1.00 & 0.08 & $1.45(0.79-2.66)$ & 1.00 & 0.23 \\
\hline Limited mobility & $3.00(1.53-5.89)$ & 1.00 & $<0.01$ & $2.47(1.16-5.28)$ & 1.00 & 0.02 \\
\hline \multicolumn{7}{|l|}{ Acute disease or } \\
\hline psychological stress & $1.02(0.61-1.71)$ & 1.00 & 0.93 & $1.12(0.66-1.89)$ & 1.00 & 0.68 \\
\hline \multicolumn{7}{|l|}{ Neuropsychological } \\
\hline problems & $2.68(1.40-5.13)$ & 1.00 & $<0.01$ & $2.11(1.09-4.10)$ & 1.00 & 0.03 \\
\hline Low BMI & $0.62(0.25-1.55)$ & 1.00 & 0.31 & $0.44(0.16-1.22)$ & 1.00 & 0.12 \\
\hline
\end{tabular}

OR = Odds Ratio $; 95 \%$ CI = 95\% Confidence Interval

Table 3

Associations of occupational level with nutritional risk and MNA®-SF sub-domains

\begin{tabular}{|c|c|c|c|c|c|c|}
\hline & \multirow{2}{*}{\multicolumn{3}{|c|}{$\begin{array}{l}\text { Crude effect } \\
\text { High occupational } \\
\text { level (ref.) }\end{array}$}} & \multicolumn{3}{|c|}{ Adjusted for age, sex } \\
\hline & & & & $\begin{array}{c}\text { Low occupational } \\
\text { level }\end{array}$ & $\begin{array}{c}\text { High occupational } \\
\text { level (ref.) }\end{array}$ & \\
\hline & OR $(95 \% \mathrm{CI})$ & OR $(95 \% \mathrm{CI})$ & $\mathbf{p}$ & OR $(95 \% \mathrm{CI})$ & OR $(95 \% \mathrm{CI})$ & $\mathbf{p}$ \\
\hline \multicolumn{7}{|l|}{ Total score } \\
\hline MNA ${ }^{\circledR}-\mathrm{SF}<12$ & $1.71(1.08-2.72)$ & 1.00 & 0.02 & $1.32(0.80-2.17)$ & 1.00 & 0.28 \\
\hline \multicolumn{7}{|l|}{ Sub-domains } \\
\hline Decreased food intake & $1.17(0.68-2.00)$ & 1.00 & 0.57 & $0.80(0.44-1.45)$ & 1.00 & 0.46 \\
\hline Weight loss & $1.97(1.11-3.49)$ & 1.00 & 0.02 & $1.65(0.91-3.00)$ & 1.00 & 0.10 \\
\hline Limited mobility & $1.87(1.10-3.18)$ & 1.00 & 0.02 & $1.81(0.96-3.43)$ & 1.00 & 0.07 \\
\hline \multicolumn{7}{|l|}{ Acute disease or } \\
\hline psychological stress & $1.80(1.05-3.10)$ & 1.00 & 0.03 & $2.08(1.18-3.66)$ & 1.00 & 0.01 \\
\hline Neuropsychological problems & $1.62(0.97-2.69)$ & 1.00 & 0.06 & $1.13(0.66-1.93)$ & 1.00 & 0.67 \\
\hline Low BMI & $0.29(0.14-0.60)$ & 1.00 & $<0.01$ & $0.18(0.07-0.46)$ & 1.00 & $<0.001$ \\
\hline
\end{tabular}

low BMI was less common in those with a low occupational level $(\mathrm{OR}=0.18,95 \% \mathrm{CI}=0.07-0.46)$.

\section{Discussion}

The aim of the current study was to investigate socioeconomic inequalities in malnutrition and sub-domains of malnutrition among community-dwelling older adults. Results from adjusted models indicated that low levels of either education or occupation were not associated with the overall risk for malnutrition, as determined by the MNA ${ }^{\circledR}$ SF. Associations between SEP and sub-domains of the MNA ${ }^{\circledR}-S F$ were observed, but these associations were not consistent across SEP indicators: educational level was related to limited mobility and neuropsychological problems, whereas occupational level was associated with acute disease/ psychological stress and low BMI.

This study adds to existing evidence showing that the relationship between socioeconomic indicators and being at risk for malnutrition is inconsistent. We found that educational level was not associated with malnutrition when adjusted for covariates. This finding is in line with a previous study among older community-dwelling adults in Poland (15), although disagrees with a study among older Italians in which a higher risk for malnutrition was associated with lower education level (14). However, this same Italian study found no evidence for 


\section{SOCIOECONOMIC POSITION AND MALNUTRITION AMONG OLDER ADULTS}

the link between occupational level or financial conditions and the risk of malnutrition. In future research, the role of income for nutritional risk may be studied in greater detail, as income may be related to differences in nutrient intake (i.e., insufficient quality and quantity of food intake), an underlying cause of poor nutritional status (26). The current study lacked information on income, and previous studies used only proxy measures for income (e.g., self-reported poverty) (15).

There was no clear pattern in the associations between SEP and sub-domains of the MNA®-SF. Limited mobility and neuropsychological problems were more prevalent among lower educated people, and acute disease/psychological distress was more common in those with a lower occupational level. Educational inequalities in mobility and neuropsychological problems have been observed before, as well as income differences in diseases (27-29). However, we would have expected these associations to be more consistent across SEP indicators, as shown in previous studies on socioeconomic inequalities in morbidity and disability (29). Surprisingly, our results showed a higher prevalence of low BMI among people with a higher occupational level. This may be explained by the low prevalence of low BMI, which limits the reliability of the analysis on this sub-domain, and by the fact that obesity - not low BMI - is usually more prevalent among older adults with a low $\operatorname{SEP}(27,29)$.

Whilst there is a paucity of literature investigating the relationship between SEP and malnutrition, the opposite is true of the geriatric condition of frailty. Multiple studies of frailty and its link to SEP have been conducted across various settings of older adults (27, 30-34). Moreover, to our knowledge, frailty has been consistently found to associate with SEP in all studies to date. Given that frailty is a common manifestation of undernutrition, we expected to find a similar relationship between SEP and malnutrition. The lack of such a relationship in our study (and that of the Polish study mentioned above (15)) was surprising and suggests that other domains of malnutrition (low physical activity, depression, lack of appetite, inadequate care and support, poor oral health amongst others) may have much more of an impact of malnutrition development than low SEP, highlighting the multifactorial nature of malnutrition.

Strengths of the present study include the large study sample size with a high cooperation rate (84.7\%), the comprehensive dataset with multiple indicators of SEP, and the use of the well-validated MNA ${ }^{\circledR}-\mathrm{SF}$ to indicate nutritional status. Despite these strengths, the study did have its limitations, including its cross-sectional design. Accordingly, results from this study do not infer causation. Furthermore, we used multiple sources of socioeconomic data to measure SEP, as recommended in older populations (35). However, unfortunately, information on income is lacking in the FRADEA study, to further complement the socioeconomic data. Another limitation may be the skewed distributions of both socioeconomic indicators, with a large proportion of the respondents that belong to the low SEP groups. However, this reflects the characteristics of the 70+ population in Spain, where many older adults of this generation started to work at early age, instead of going to high school or university.

Our study has implications for managing and intervening on malnutrition in daily practice. Since malnutrition has serious consequences for health and functioning of older adults, it is important to develop intervention strategies aimed at preventing or reducing malnutrition. This may lead to improved outcomes and may reduce healthcare costs (36). Based on the evidence from the current study and on the inconsistencies found in previous studies, it is not recommended to mainly focus these interventions on lower socioeconomic groups. Intervention strategies may be developed for community-dwelling older adults in general, and do not have to be SEP-specific. However, still more evidence is needed from longitudinal studies, to see whether SEP is related to developing malnutrition over time. This may be addressed in future research, as well as comparisons between countries and settings.

In conclusion, this study did not provide convincing evidence for socioeconomic inequalities in malnutrition among older adults. In adjusted models, educational level and occupational level were not associated with nutritional risk. Some sub-domains of the MNA ${ }^{\circledR}-\mathrm{SF}$ were associated with SEP, but these associations were not consistent across socioeconomic indicators. Because of the severe consequences of malnutrition in terms of adverse health events and increased healthcare costs (36), it is important to develop interventions aimed at the prevention of malnutrition or at improving nutritional status. The findings of the current study suggest that these interventions do not have to be SEP specific. Additionally, nutritional screening should be performed for all older people, as malnutrition is a condition that can appear in any older adult, regardless of their socioeconomic group.

Acknowledgments/Funding: The FRADEA study was supported by the CastillaLa Mancha Health Research Foundation (FISCAM) [grant number Pi2006/42], and CIBERFES, Instituto de Salud Carlos III, Ministerio de Economía y Competitividad, España (Ayuda cofinanciada por el Fondo Europeo de Desarrollo Regional FEDER Una Manera de hacer Europa). Emiel O. Hoogendijk was supported by an NWO/ZonMw Veni fellowship [grant number 91618067]. Elsa Dent was supported by a National Health and Medical Council (NHMRC) Early Career fellowship [grant number APP1112672]. The funders had no role in the design or publication of the manuscript.

Conflict of interest: The authors declare that they have no conflict of interest.

Ethical Standards: The FRADEA study received approval by the Albacete health region Independent Ethics Committee and the Albacete University Hospital Ethics Committee. All participants provided signed informed consent.

Open Access: This article is distributed under the terms of the Creative Commons Attribution 4.0 International License (http://creativecommons.org/licenses/by/4.0/), which permits use, duplication, adaptation, distribution and reproduction in any medium or format, as long as you give appropriate credit to the original author(s) and the source, provide a link to the Creative Commons license and indicate if changes were made.

\section{References}

1. Poli S, Cella A, Puntoni M, Musacchio C, Pomata M, Torriglia D, Vello N, Molinari B, Pandolfini V, Torrigiani C, Pilotto A. Frailty is associated with socioeconomic and lifestyle factors in community-dwelling older subjects. Aging Clin Exp Res 


\section{THE JOURNAL OF NUTRITION, HEALTH \& AGINGC}

2017:29:721-728.

2. Hoogendijk EO, Heymans MW, Deeg DJH, Huisman M. Socioeconomic inequalities in frailty among older adults: results from a 10-year longitudinal study in the Netherlands. Gerontology 2018;64:157-164.

3. Haider SI, Johnell K, Weitoft GR, Thorslund M, Fastbom J. The influence of educational level on polypharmacy and inappropriate drug use: a register-based study of more than 600,000 older people. J Am Geriatr Soc 2009;57:62-69.

4. Martinez-Reig M, Gomez-Arnedo L, Alfonso-Silguero SA, Juncos-Martinez G, Romero L, Abizanda P. Nutritional risk, nutritional status and incident disability in older adults. The FRADEA study. J Nutr Health Aging 2014;18:270-276.

5. Jimenez-Redondo S, Beltran de Miguel B, Gavidia Banegas J, Guzman Mercedes L, Gomez-Pavon J, Cuadrado Vives C. Influence of nutritional status on health-related quality of life of non-institutionalized older people. J Nutr Health Aging 2014;18:359364.

6. Dent E, Visvanathan R, Piantadosi C, Chapman I. Nutritional screening tools as predictors of mortality, functional decline, and move to higher level care in older people: a systematic review. J Nutr Gerontol Geriatr 2012;31:97-145.

7. Kaiser MJ, Bauer JM, Ramsch C, Uter W, Guigoz Y, Cederholm T, Thomas DR, Anthony PS, Charlton KE, Maggio M, Tsai AC, Vellas B, Sieber CC. Frequency of malnutrition in older adults: a multinational perspective using the mini nutritional assessment. J Am Geriatr Soc 2010;58:1734-1738.

8. van der Pols-Vijlbrief R, Wijnhoven HA, Schaap LA, Terwee CB, Visser M. Determinants of protein-energy malnutrition in community-dwelling older adults: a systematic review of observational studies. Ageing Res Rev 2014;18:112-131.

9. Favaro-Moreira NC, Krausch-Hofmann S, Matthys C, Vereecken C, Vanhauwaert E, Declercq A, Bekkering GE, Duyck J. Risk factors for malnutrition in older adults: a systematic review of the literature based on longitudinal data. Advances in nutrition 2016;7:507-522.

10. Strathmann S, Lesser S, Bai-Habelski J, Overzier S, Paker-Eichelkraut HS, Stehle P, Heseker H. Institutional factors associated with the nutritional status of residents from 10 German nursing homes (ErnSTES study). J Nutr Health Aging 2013;17:271-276.

11. Fotso JC, Kuate-Defo B. Socioeconomic inequalities in early childhood malnutrition and morbidity: modification of the household-level effects by the community SES . Health Place 2005; 11:205-225

12. Kabir ZN, Ferdous T, Cederholm T, Khanam MA, Streatfied K, Wahlin A. Min Nutritional Assessment of rural elderly people in Bangladesh: the impact of demographic, socio-economic and health factors. Public Health Nutr 2006;9:968-974.

13. Van de Poel E, Hosseinpoor AR, Speybroeck N, Van Ourti T, Vega J. Socioeconomic inequality in malnutrition in developing countries. Bulletin of the World Health Organization 2008;86:282-291.

14. Timpini A, Facchi E, Cossi S, Ghisla MK, Romanelli G, Marengoni A. Selfreported socio-economic status, social, physical and leisure activities and risk for malnutrition in late life: a cross-sectional population-based study. J Nutr Health Aging 2011;15:233-238.

15. Krzyminska-Siemaszko R, Mossakowska M, Skalska A, Klich-Raczka A, Tobis S, Szybalska A, Cylkowska-Nowak M, Olszanecka-Glinianowicz M, Chudek J, Wieczorowska-Tobis K. Social and economic correlates of malnutrition in Polish elderly population: the results of PolSenior study. J Nutr Health Aging 2015;19:397402.

16. Kaiser MJ, Bauer JM, Ramsch C, Uter W, Guigoz Y, Cederholm T, Thomas DR, Anthony P, Charlton KE, Maggio M, Tsai AC, Grathwohl D, Vellas B, Sieber CC. Validation of the Mini Nutritional Assessment short-form (MNA-SF): a practical too for identification of nutritional status. J Nutr Health Aging 2009;13:782-788.

17. Kondrup J, Allison SP, Elia M, Vellas B, Plauth M. ESPEN guidelines for nutrition screening 2002. Clin Nutr 2003;22:415-421.

18. Abizanda Soler P, Lopez-Torres Hidalgo J, Romero Rizos L, Lopez Jimenez M, Sanchez Jurado PM, Atienzar Nunez P, Esquinas Requena JL, Garcia Nogueras I, Hernandez Zegarra P, Bardales Mas Y, Campos Rosa R, Martinez Penalver M, de la Osa Nieto E, Carion Gonzalez M, Ruiz Gomez A, Aguilar Cantos C, Manueco
Delicado P, Oliver Carbonell JL. Frailty and dependence in Albacete (FRADEA study): reasoning, design and methodology. Rev Esp Geriatr Gerontol 2011;46:81-88.

19. Domingo Salvany A, Marcos Alonso J. Propuesta de un indicador de la «clase social» basado en la ocupación. Gaceta Sanitaria 1989;3:320-326.

20. Kelaiditi E, Demougeot L, Lilamand M, Guyonnet S, Vellas B, Cesari M. Nutritiona status and the incidence of pneumonia in nursing home residents: results from the INCUR study. J Am Med Dir Assoc 2014;15:588-592.

21. Mahoney FI, Barthel DW. Functional evaluation: the Barthel Index. Maryland state medical journal 1965;14:61-65.

22. Charlson M, Szatrowski TP, Peterson J, Gold J. Validation of a combined comorbidity index. J Clin Epidemiol 1994:47:1245-1251.

23. Folstein MF, Folstein SE, McHugh PR. «Mini-mental state». A practical method for grading the cognitive state of patients for the clinician. J Psychiatr Res 1975;12:189 198

24. Fried LP, Tangen CM, Walston J, Newman AB, Hirsch C, Gottdiener J, Seeman T, Tracy R, Kop WJ, Burke G, McBurnie MA. Frailty in older adults: evidence for a phenotype. J Gerontol A Biol Sci Med Sci 2001;56:M146-156.

25. Abizanda P, Romero L, Sanchez-Jurado PM, Martinez-Reig M, Alfonso-Silguero SA, Rodriguez-Manas L. Age, frailty, disability, institutionalization, multimorbidity or comorbidity. Which are the main targets in older adults? J Nutr Health Aging 2014;18:622-627.

26. Bianchetti A, Rozzini R, Carabellese C, Zanetti O, Trabucchi M. Nutritional intake, socioeconomic conditions, and health status in a large elderly population. J Am Geriat Soc 1990;38:521-526.

27. Hoogendijk EO, van Hout HP, Heymans MW, van der Horst HE, Frijters DH, Broese van Groenou MI, Deeg DJ, Huisman M. Explaining the association between educational level and frailty in older adults: results from a 13-year longitudinal study in the Netherlands. Ann Epidemiol 2014;24:538-544.

28. Koster A, Bosma H, Kempen GI, van Lenthe FJ, van Eijk JT, Mackenbach JP. Socioeconomic inequalities in mobility decline in chronic disease groups (asthma/ COPD, heart disease, diabetes mellitus, low back pain): only a minor role for disease severity and comorbidity. J Epidemiol Community Health 2004;58:862-869.

29. Koster A, Bosma H, Broese van Groenou MI, Kempen GI, Penninx BW, van Eijk JT, Deeg DJ. Explanations of socioeconomic differences in changes in physical function in older adults: results from the Longitudinal Aging Study Amsterdam. BMC Public Health 2006;6:244.

30. Dent E, Kowal P, Hoogendijk EO. Frailty measurement in research and clinical practice: a review. Eur J Intern Med 2016;31:3-10.

31. Bandeen-Roche K, Seplaki CL, Huang J, Buta B, Kalyani RR, Varadhan R, Xue QL, Walston JD, Kasper JD. Frailty in older adults: a nationally representative profile in the United States. J Gerontol A Biol Sci Med Sci 2015;70:1427-1434.

32. Soler-Vila H, Garcia-Esquinas E, Leon-Munoz LM, Lopez-Garcia E, Banegas JR, Rodriguez-Artalejo F. Contribution of health behaviours and clinical factors to socioeconomic differences in frailty among older adults. J Epidemiol Community Health 2016;70:354-360.

33. Szanton SL, Seplaki CL, Thorpe RJ, Jr., Allen JK, Fried LP. Socioeconomic status is associated with frailty: the Women's Health and Aging Studies. J Epidemiol Community Health 2010;64:63-67.

34. Woo J, Chan R, Leung J, Wong M. Relative contributions of geographic, socioeconomic, and lifestyle factors to quality of life, frailty, and mortality in elderly. PLoS One 2010;5:e8775.

35. Grundy E, Holt G. The socioeconomic status of older adults: how should we measure it in studies of health inequalities? J Epidemiol Community Health 2001;55:895-904.

36. Martinez-Reig M, Aranda-Reneo I, Pena-Longobardo LM, Oliva-Moreno J, BarconsVilardell N, Hoogendijk EO, Abizanda P. Use of health resources and healthcare costs associated with nutritional risk: The FRADEA study. Clin Nutr, 2017;in press, DOI: 10.1016/j.clnu.2017.05.021 